\title{
Genetic parameters of beef traits of Limousin and Charolais progeny-tested AI sires
}

\author{
Marie-Noëlle Fouilloux ${ }^{\mathrm{a}, \mathrm{b} *}$, Gilles Renand ${ }^{\mathrm{a}}$, Jacques Gaillard ${ }^{\mathrm{b}}$, \\ François Ménissier ${ }^{\mathrm{a}}$ \\ ${ }^{a}$ Station de génétique quantitative et appliquée, Institut national \\ de la recherche agronomique, 78352 Jouy-en-Josas, France \\ ${ }^{\mathrm{b}}$ Institut de l'élevage, Station de génétique quantitative et appliquée, 78352 \\ Jouy-en-Josas, France
}

(Received 10 November 1998; accepted 3 September 1999)

\begin{abstract}
Sire selection efficiency depends on the knowledge of accurate genetic parameters. In France, artificial insemination (AI) sires are selected according to their own performances and those of their progeny, which are both recorded in test stations. Genetic parameters among progeny traits were estimated using multi-trait REML (restricted estimation of maximum likelihood) analyses in Charolais and Limousin breeds. The expected decrease in genetic variability algebraically calculated among progeny traits due to the selection of sires was not observed. This selection was not a strict truncation. Heritabilities of traits measured on progeny are moderate for growth traits, morphology and live fatness scores (from 0.14 to 0.38 ) and slightly higher for dressing percentage and carcass fatness score ( 0.50 and 0.44 , respectively). Genetic correlations among progeny traits depended on traits, selection programme and breed. Carcass weight and morphology were highly genetically linked to corresponding live traits (live weight and conformation, respectively). They can, therefore, be easily improved through indirect selection in contrast to carcass fatness which has only a small genetic correlation with live traits. (C) Inra/Elsevier, Paris
\end{abstract}

genetic parameters / live and carcass traits / Charolais and Limousin breeds / selection

Résumé - Paramètres génétiques des aptitudes bouchères des taureaux d'insémination artificielle Limousins et Charolais contrôlés sur descendance. L'efficacité de la sélection des reproducteurs dépend de l'exactitude des paramètres génétiques utilisés. En France, les taureaux d'insémination artificielle sont sélectionnés à partir de leurs performances propres et celles de leurs descendants mesurées en station de

\footnotetext{
* Correspondence and reprints

E-mail: Fouilloux@dga.jouy.inra.fr
} 
contrôle. Les paramètres génétiques des performances des descendants ont été estimés en race Charolaise et Limousine à l'aide d'un REML (Estimation du Maximum de Vraisemblance Restreint) - multicaractère. La réduction calculée algébriquement de la variabilité génétique des performances des descendants due à la sélection des pères, n'a pas été observée. Cette sélection n'a pas été faite par troncature stricte. L'héritabilité des caractères de croissance, de morphologie et d'état d'engraissement est modérée (comprise entre 0,14 et 0,38 ). Celle du rendement de carcasse et de la note de gras interne est plus élevée $(0,50$ et 0,44 , respectivement). Les corrélations génétiques dépendent, notamment, des caractères analysés, du programme de sélection et de la race. Le poids et la conformation des carcasses sont fortement corrélés génétiquement à des caractères mesurables sur l'animal vivant. Ils sont donc aisément améliorables par sélection indirecte contrairement à l'état d'engraissement des carcasses qui n'apparaît que peu lié génétiquement aux caractères contrôlés en vif. (C) Inra/Elsevier, Paris

paramètres génétiques / caractères en vif et d'abattage / races Charolaise et Limousine / sélection

\section{INTRODUCTION}

In France, beef traits of artificial insemination (AI) bulls are improved by a three-step sequential selection. The first step is based on pedigree and performances at weaning. The second step is based on post-weaning performances of bulls recorded in central test stations. The last step is based on the performances of a sample of the male progeny of these bulls fattened in progeny test stations. Breeding values of these sires for beef production are currently estimated using the latter two data sets [1].

Since the beginning of the 1980s, heritabilities of beef traits currently used in genetic evaluation programmes in France have been based on the estimates given by Renand and Gaillard [29], Renand [25, 26] and Renand et al. [30] in different beef breeds, using the Henderson method 3 without a relationship matrix among sires. Since the accuracy of genetic evaluations and consequently the efficiency of selection partly depend on the use of correct sound parameters (heritabilities and genetic correlations), these estimates need to be reconsidered for two reasons: 1) more recent information is available in these selection programmes; 2 ) variance component estimations can be obtained with more suitable methods, such as restricted estimation of maximum likelihood (REML), known to be the method of choice for most situations in animal breeding. Sire selection based on their own performance prior to their progeny testing was expected to modify the subsequent genetic variability $[4,8]$. Then, an unbiased estimation of genetic parameters requires that the data used for selection decisions (performance and pedigree up to the base population) be included in the analysis [35]. Journaux [13] estimated genetic parameters of a trait observed for progeny and a trait observed for the sires using a bivariate REML approach. Nowadays, such multivariate REML estimates could allow, to a certain extent, the estimation of variance components taking into account the information used for selection.

The objective of this paper was to estimate the genetic parameters to be used for progeny testing after checking whether the previous selection of sires based on their own performance should be taken into account. 


\section{MATERIAL AND METHODS}

\subsection{Design of testing procedures in the French AI programmes}

In each of the specialised beef breeds in France, two types of programmes exist for selecting AI bulls depending on whether they are predominantly used for terminal crossbreeding or for pure-breeding.

Each year, new potential AI bulls were bought by AI co-operatives at weaning in nucleus herds and gathered in central test stations (50-70 per year on average). The actual information used by AI co-operatives for selecting these calves was not known. Two or three groups of contemporary calves (born within a 6-week period) were then tested for a fixed period length up to approximately 16 months of age. At the end of the test, the best bulls to be progeny tested were selected according to an index combining three or four traits recorded in these central stations. These performances were final weight, feed efficiency and muscling score for selecting terminal crossbreeding AI bulls. Skeletal frame score was added when AI bulls were used for pure-breeding [1]. Semen quality of selected bulls was assessed before progeny testing. This selection step was not a strict truncation (figure 1) because some sires with high indexes were eliminated either for bad semen quality or other defects.

Bulls selected (on average 8-13 per year) were randomly mated to about 100 adult cows in commercial herds. Three reference bulls were simultaneously used. Approximately 20-30 male calves per tested bull and per reference sires at 15-20 days (crossbred) or 6-7 months (pure-bred) of age were bought and set in the test stations. Crossbred calves were raised in a nursery until the beginning of the performance test (5-6 months). The performance test of the pure-bred calves started after 1 month of adaptation. At the beginning of the performance tests, young bulls were gathered in age-contemporary groups (variation of 1 month maximum). During the test period, male calves were intensively fattened with corn silage distributed ad libitum and supplemented with protein feed. They were slaughtered under uniform conditions at a fixed age or fixed weight depending on the selection programme. Carcass traits were recorded. In each progeny test station, batches for different years were genetically connected through three national reference sires [1].

\subsection{Animals considered}

The genetic parameters of live and slaughter traits were estimated using two sets of performances recorded in Charolais and Limousin progeny test stations. In both breeds, pure-bred and crossbred progeny tests exist. In this analysis, Limousin bulls were progeny tested on pure-bred young bulls slaughtered at the fixed age of 16 months and Charolais bulls were progeny tested on crossbred young bulls (Normand and Friesian dams) slaughtered at a fixed weight of $600-650 \mathrm{~kg}$ depending on the year.

A total of 131 Limousin and 145 Charolais sires was progeny tested on 4532 and 3519 young bulls, over 11-12 consecutive years, respectively. Most of these sires were previously tested in central test stations. 
(Charolais)

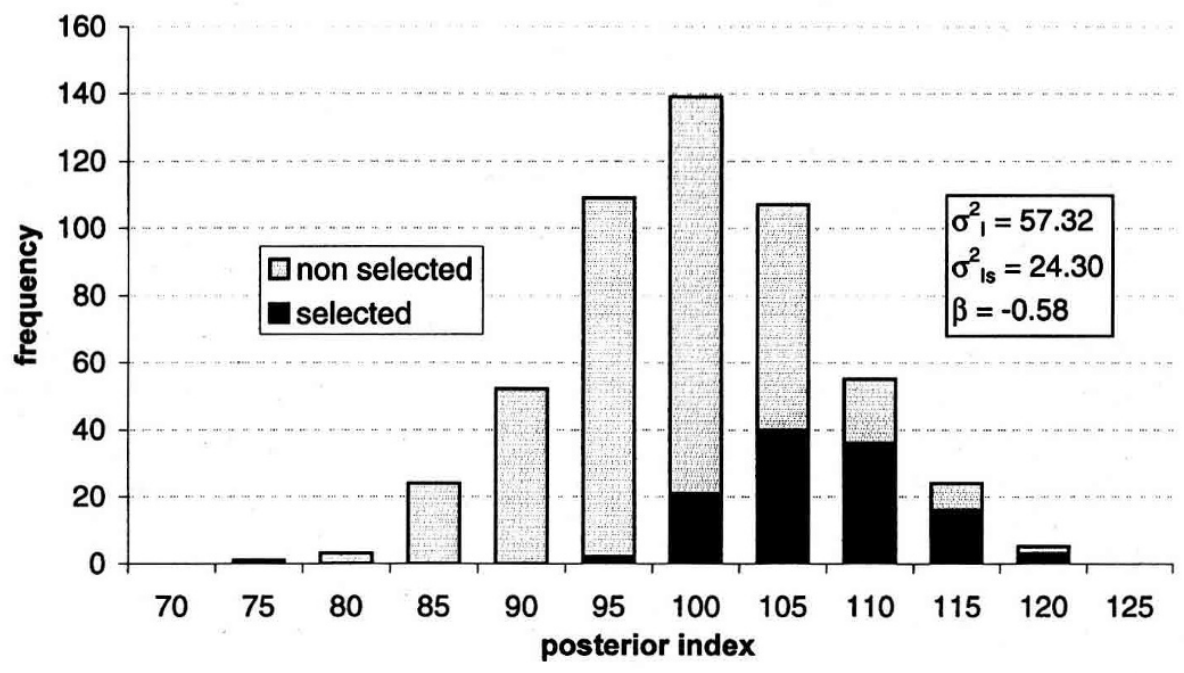

(Limousin)

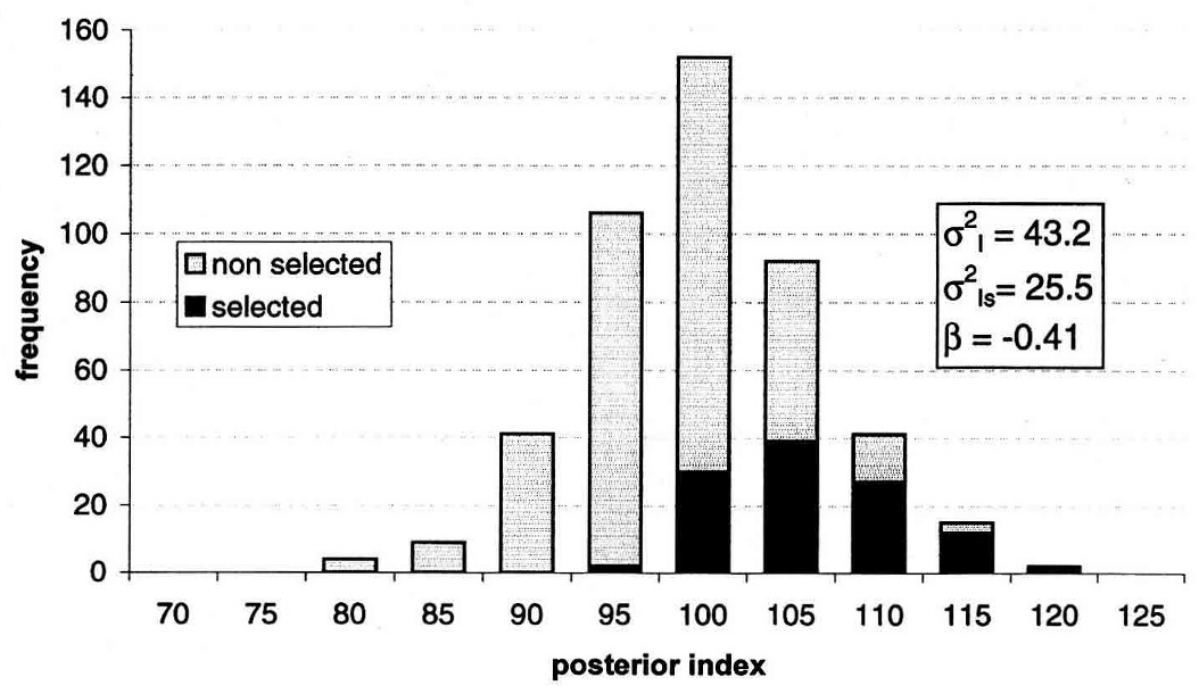

Figure 1. Distribution of the sire selection criteria a posteriori in the selected and non-selected populations.

\subsection{Performances recorded in progeny test station}

Owing to the strict procedures and the restricted number of animals in the station, many performances concerning growth and conformation could be 
accurately recorded before or after slaughter. The beef traits analysed in this study were:

- growth traits: average daily gain during the fattening period (ADG), initial weight (IW) and live weight (LW) adjusted by interpolation from the two nearest weights to 300 and 480 days, respectively, in the Limousin progeny and to 163 and 450 days in the Charolais crossbred progeny;

- slaughter yield: dressing percentage (DP) defined as the ratio of hot carcass weight to final live weight;

- morphology scores: live muscling (LM), carcass muscling (CM) and live skeletal frame (LS) scores;

- fatness scores: live fatness (LF) and carcass fatness (CF) scores. As carcasses were systematically trimmed at slaughter, CF was scored for the amount of pelvic, kidney and internal fats.

Scores were given by a very limited number of experienced technicians in each station at the very end of the test period (LM, LS, LF) and at slaughter (CM, CF).

\subsection{Effect of selection of sires on the genetic variability of progeny traits}

\subsubsection{Effect of step 2 selection}

In order to study the impact of the selection of sires (step 2) on the genetic variability of progeny traits three different estimates of genetic parameters were compared. This selection was based on the sire own performances measured in the central test station. In the Charolais programme, a set of four traits measured on progeny was studied: two live traits (live weight (LW) and live muscling score (LM)) and two slaughter performances (dressing percentage (DP) and carcass fatness score (CF)).

- The first estimates $\left(h^{2}\right.$ and $\left.r_{g}\right)$ were obtained on these four progeny traits analysed simultaneously with the three performance traits of sires used for selecting bulls on their own performances in the test station (final weight, feed efficiency and live muscling score). The progeny trait (co)variances were described with a sire model while the sire performance (co) variances were described with an animal model. Since all the data presumably used for selecting the sires were included in the analysis, these estimates were considered to be free from the influence of selection in step 2 .

- The second estimates $\left(h_{a}^{2}\right.$ and $r_{a g}$ ) were obtained on the four progeny traits only, described with a sire model. These apparent genetic parameters might have been biased by selection.

- The third estimates $\left(h_{e}^{2}\right.$ and $r_{e g}$ ) were algebraically derived from the first ones taking into account the reduction in variance of traits among selected sires. Selection at the end of the performance tests in the central test station (step 2) was assumed to be only made on a selection index combining final weight $\left(P_{\mathrm{FW}}\right)$, live muscling score $\left(P_{\mathrm{LM}}\right)$ and feed efficiency $\left(P_{\mathrm{FE}}\right)$. A posterior index $(I)$ [20] was obtained from the observed selection differentials of each trait $\left(\bar{P}_{i_{s}}-\bar{P}_{i}\right)$, where $\bar{P}_{i}$ and $\bar{P}_{i_{s}}$ were the means of sires for the $i$ th trait 
before and after selection:

$$
I=1.10 \frac{\left(\bar{P}_{\mathrm{FW}_{s}}-\bar{P}_{\mathrm{FW}}\right)}{\sigma_{\mathrm{FW}}}+1.13 \frac{\left(\bar{P}_{\mathrm{LM}_{s}}-\bar{P}_{\mathrm{LM}}\right)}{\sigma_{\mathrm{LM}}}+0.99 \frac{\left(\bar{P}_{\mathrm{FE}}-\bar{P}_{\mathrm{FE}}\right)}{\sigma_{\mathrm{FE}}}
$$

Using this index with a threshold selection would have led to the observed selection differential for each trait.

In the Charolais programme, 118 out of the 145 progeny-tested sires were selected among 519 bulls tested in the central station. The observed selection differential was about 7.00 on that posterior index $(I)$. Because the observed variance before selection $\left(\sigma_{I}^{2}\right)$ was 57.3 , selection intensity was equal to 0.93 . The variance observed among selected bulls $\left(\sigma_{I s}^{2}\right)$ was $24.3\left(43 \%\right.$ of $\left.\sigma_{I}^{2}\right)$ and the relative reduction of variance, $\beta=\left(\sigma_{I s}^{2}-\sigma_{I}^{2}\right) / \sigma_{I}^{2}$ was -0.58 .

Such an investigation was carried out in the Limousin programme, where 112 sires were progeny tested out of 470 bulls tested in the central station. Similarly to the Charolais analysis, three sets of genetic parameters among progeny live weight, live muscling score, dressing percentage and carcass fatness score were estimated according to different models considering or not the selection of bulls in the performance test station. Limousin bulls were selected according to their final weight (FW), feed efficiency (FE), live muscling score (LM) and skeletal frame score (LS). A posterior index was calculated combining the FW, FE, LM and LS. The observed selection differential was about 6.34 for that posterior index $(I)$ with a selection intensity of 0.96 . The observed variances of the posterior index $(I)$ before and after selection were equal to $\sigma_{I}^{2}=43.2$ and $\sigma_{I s}^{2}=25.5$, respectively $\left(\sigma_{I s}^{2} / \sigma_{I}^{2}=59 \%\right)$. The relative reduction of the index variance $(\beta)$ was equal to -0.41 .

Knowing the weights $\left(b_{i}\right)$ of traits $(i)$ in the selection index $\left(I=\sum_{i} b_{i} P_{i}\right)$, the relative reduction of index variance $(\beta)$ and the correct genetic parameters $\left(h^{2}\right.$ and $r_{g}$ ), the genetic parameters in this sample of selected sires that were expected to be observed $\left(h_{e j}^{2}, h_{e k}^{2}\right.$ and $\left.r_{e g_{i j}}\right)$ for progeny traits $(j$ and $k)$ can be calculated algebraically. The formulae initially given by Robertson [32] for single trait selection were extended to a selection on a selection index [23] (see Appendix):

$$
\begin{aligned}
h_{e j}^{2}= & \frac{\left(\sigma_{I}^{2}+\beta\left(\sum_{i} b_{i} r_{g_{i j}} \sigma_{g_{i}}\right)^{2}\right)}{\sigma_{I}^{2}+0.25 \beta\left(\sum_{i} b_{i} r_{g_{i j}} \sigma_{g_{i}}\right)^{2} h_{j}^{2}} h_{j}^{2} \\
r_{e g_{j k}}= & \frac{\left(r_{g_{j k}} \sigma_{I}^{2}+\beta\left(\sum_{i} b_{i} r_{g_{i j}} \sigma_{g_{i}}\right)\left(\sum_{i} b_{i} r_{g_{i k}} \sigma_{g_{i}}\right)\right)}{\sqrt{\left(\sigma_{I}^{2}+\beta\left(\sum_{i} b_{i} r_{g_{i j}} \sigma_{g_{i}}\right)^{2}\right)\left(\sigma_{I}^{2}+\beta\left(\sum_{i} b_{i} r_{g_{i k}} \sigma_{g_{i}}\right)^{2}\right)}}
\end{aligned}
$$


where $\sigma_{g_{i}}$ was the genetic standard deviation of trait $i$ in the sire selection index.

\subsubsection{Effect of step 1 selection}

As bulls were previously selected according to some information at weaning before being performance tested in the station, the genetic variability of traits measured on progeny might eventually have been affected by that step 1 selection.

In order to estimate the impact of selection at weaning on the progeny genetic parameters, weaning performances of all contemporary males raised in the same herds should be considered. Performances at weaning of male calves from the selected bull's contemporary-herd group were extracted from a data set used in a French beef bull evaluation programme on performances recorded in farms [1]. In the Charolais breed, weaning performances of 15143 young bulls were available ( 419 tested in the central station). In the Limousin breed, weaning performances of 14909 young bulls were available (407 tested in the central station). Such an amount of information prevents one from integrating weaning traits together with progeny traits in a multiple trait analysis for estimating genetic parameters free of that selection effect. It was only possible to use the algebraic formulae ( 1 and 2 ) for predicting what should have been the impact of that selection. The use of these formulae required, however, that true $\beta$ and genetic parameters be known.

As the actual criteria used to choose tested bulls were unknown, an intensity of selection at weaning was calculated postulating that AI co-operatives did select the male calves according to weight (WW), muscularity (WM) and, in the Limousin programme, skeletal frame (WS) at weaning.

'Superiority' of each selected male was calculated as the standardised difference between its performances (WW, WM or WS) and the average of male calves from its contemporary-herd group:

$$
S_{h j i}=\frac{\left(P_{h j i}-\bar{P}_{h i}\right)}{\sigma_{h i}}
$$

where $S_{h j i}$ was the 'superiority' for trait $i(i=\mathrm{WW}, \mathrm{WM}$ or WS) of selected calf $j$ raised in the contemporary-herd group $h ; P_{h j i}$ was the performance of this calf $j$ for trait $i$; $\bar{P}_{h i}$ was the mean of the male contemporary-herd group $h$; and $\sigma_{h i}$ was the standard deviation in this group.

A posterior selection index $(I)$ was calculated, combining these 'superiorities' for WW, WM and, in the Limousin programme, WS.

In the Charolais programme, the observed selection differential was about 35.5 for that posterior index $(I)$ and the observed variance $\left(\sigma_{I}^{2}\right)$ before selection was 400.0. Hence, the observed selection intensity was equal to 1.78. The variance of the posterior index $(I)$ after selection was $\sigma_{I s}^{2}=186.0\left(\sigma_{I s}^{2} / \sigma_{I}^{2}=\right.$ $47 \%$ ). The relative reduction of the index variance $(\beta)$ was therefore equal to -0.54 .

In the Limousin programme, the observed selection differential was about 30.3 for that posterior index $(I)$ and the observed variance $\left(\sigma_{I}^{2}\right)$ before selection was 400.0. Hence, the observed selection intensity was equal to 1.52 . The 
Table I. General statistics: mean \pm standard deviation*

\begin{tabular}{lcccc}
\hline & Unit & Symbol & Limousin & Charolais crosses \\
\hline Initial age** & day & & $300 \pm 28$ & $163 \pm 22$ \\
Initial weight & $\mathrm{kg}$ & $\mathrm{IW}$ & $349 \pm 54$ & $210 \pm 24$ \\
Average daily gain & $\mathrm{g} \cdot \mathrm{j}^{-1}$ & $\mathrm{ADG}$ & $1395 \pm 179$ & $1191 \pm 117$ \\
Final live weight** & $\mathrm{kg}$ & $\mathrm{LW}$ & $597 \pm 52$ & $559 \pm 40$ \\
Slaughter age & $\mathrm{day}$ & & $482 \pm 4$ & $520 \pm 38$ \\
Slaughter weight & $\mathrm{kg}$ & & $603 \pm 52$ & $630 \pm 17$ \\
Dressing percentage & $\%$ & $\mathrm{DP}$ & $62.0 \pm 1.5$ & $57.1 \pm 2.0$ \\
Live muscling score & $/ 100 \mathrm{pt}$ & $\mathrm{LM}$ & $62.9 \pm 9.3$ & $63.0 \pm 8.8$ \\
Carcass muscling score & $/ 100 \mathrm{pt}$ & $\mathrm{CM}$ & $69.5 \pm 8.3$ & $56.3 \pm 7.6$ \\
Live skeletal frame score & $/ 100 \mathrm{pt}$ & $\mathrm{LS}$ & $59.3 \pm 8.8$ & $63.7 \pm 5.7$ \\
Live fatness score & $/ 100 \mathrm{pt}$ & $\mathrm{LF}$ & $69.6 \pm 10.5$ & $72.4 \pm 7.7$ \\
Carcass internal fatness score & $/ 100 \mathrm{pt}$ & $\mathrm{CF}$ & $57.8 \pm 10.5$ & $54.8 \pm 7.1$ \\
\hline
\end{tabular}

* Within year batch standard deviation.

** Adjusted to 300 and 163 days in the Limousin and the Charolais programmes, respectively.

*** Adjusted to 480 and 450 days in the Limousin and the Charolais programmes, respectively.

variance of the posterior index $(I)$ after selection was $\sigma_{I s}^{2}=179.3\left(\sigma_{I s}^{2} / \sigma_{I}^{2}=\right.$ $45 \%)$. The relative reduction of the index variance $(\beta)$ was equal to -0.55 .

Since the true genetic correlations $\left(r_{i j}\right)$ between weaning traits on farms and traits recorded in the progeny test were not known, those estimated between post-weaning traits of sires (LW for WW, LM for WM and LS for WS) and traits recorded in the progeny test measured in the stations (tables $I I$ and $I I I)$ have been considered as the soundest correlations. Heritabilities $\left(h_{j}^{2}\right)$ of progeny performances estimated jointly to the sire's own performance (see section 2.4.1) were considered as the most reliable.

\subsection{Models of analysis and methods}

\subsubsection{Models}

In both breeds, the models of analysis of progeny traits included fixed environmental effects and random sire effect(s). There were no genetic relationships among dams and between dams and sires. Genetic relationships among sires took into account up to two generations of ancestors.

The following models were used, subsequently to an analysis of variance that tested the significance of the fixed effects (General Linear Model, SAS).

In both breeds, the main fixed effects were calving parity of the dams (calv: 2, 3, 4, 5 and over), region of origin (orig) and age-contemporary group (cont) of the young bulls. Age-contemporary groups corresponded to age-test groups in the station. Other fixed effects included: in the Limousin model, a management system up to weaning (manag: indoor or outdoor weaned calves); in the Charolais model: the breed of the dam (breed: Holstein-Friesian or Normand) and health status in the nursery (pulm and diges: occurrence or 
Table II. Effect of the selection of sires on the genetic parameters of progeny traits in the Charolais breed.

\begin{tabular}{|c|c|c|c|c|c|c|}
\hline & & & LW & LM & DP & $\mathrm{CF}$ \\
\hline Sire traits & $\begin{array}{c}\text { FW } \\
\text { FE } \\
\text { LM }\end{array}$ & & $\begin{array}{r}0.54 \\
0.30 \\
-0.13 \\
\end{array}$ & $\begin{array}{r}0.10 \\
-0.03 \\
0.63\end{array}$ & $\begin{array}{r}-0.30 \\
0.14 \\
0.20\end{array}$ & $\begin{array}{r}0.15 \\
-0.10 \\
-0.12\end{array}$ \\
\hline & LW & $\begin{array}{c}S+P \\
P_{a} \\
P_{e 2} \\
P_{e 1}\end{array}$ & $\begin{array}{l}0.34 \\
0.32 \\
0.25 \\
0.34\end{array}$ & $\begin{array}{l}0.18 \\
0.20 \\
0.05 \\
0.15\end{array}$ & $\begin{array}{l}-0.19 \\
-0.19 \\
-0.43 \\
-0.19\end{array}$ & $\begin{array}{l}0.10 \\
0.09 \\
0.04 \\
0.10\end{array}$ \\
\hline $\begin{array}{l}\text { Progeny } \\
\text { traits }\end{array}$ & LM & $\begin{array}{c}S+P \\
P_{a} \\
P_{e 2} \\
P_{e 1}\end{array}$ & & $\begin{array}{l}0.39 \\
0.36 \\
0.37 \\
0.35\end{array}$ & $\begin{array}{l}0.60 \\
0.57 \\
0.57 \\
0.64\end{array}$ & $\begin{array}{l}-0.20 \\
-0.20 \\
-0.24 \\
-0.21\end{array}$ \\
\hline & DP & $\begin{array}{c}S+P \\
P_{a} \\
P_{e 2} \\
P_{e 1}\end{array}$ & & & $\begin{array}{l}0.46 \\
0.44 \\
0.42 \\
0.46\end{array}$ & $\begin{array}{l}-0.30 \\
-0.31 \\
-0.35 \\
-0.30\end{array}$ \\
\hline & $\mathrm{CF}$ & $\begin{array}{c}S+P \\
P_{a} \\
P_{e 2} \\
P_{e 1}\end{array}$ & & & & $\begin{array}{l}0.48 \\
0.48 \\
0.47 \\
0.48\end{array}$ \\
\hline
\end{tabular}

FW: final weight; LW: age-adjusted live weight; FE: feed efficiency; LM: live muscling score; DP: dressing percentage; CF: carcass fatness score.

Sire trait section: genetic correlations between sire and progeny traits.

Progeny trait section: first line: $S+P$, progeny and performance tests used simultaneously for estimating sound genetic parameters $\left(h^{2}\right.$ and $r_{g}$ considered free of sire selection effect); second line: $P_{a}$, progeny test used alone for estimating apparent genetic parameters $\left(h_{a}^{2}\right.$ and $r_{a g}$; potentially biased); lower lines: genetic parameters that were expected to be observed $\left(h_{e}^{2}\right.$ and $\left.r_{e g}\right)$ as a consequence of sire selection step 2 $\left(P_{e 2}\right)$ or step $1\left(P_{e 1}\right)$.

In the diagonal: heritabilities $\left(h^{2}\right)$; above the diagonal: genetic correlations $\left(r_{g}\right)$.

absence of pulmonary or digestive troubles). In both breeds, average daily gain was regressed on initial age ( $\beta \mathrm{Cov})$. Muscling (LM, CM), skeletal (LS) and fatness (LF, CF) scores were regressed on final age in the Limousin breed and on final weight in the Charolais breed ( $\beta \mathrm{Cov})$.

Ch.: $y_{i j}=$ cont $_{i j}+\operatorname{calv}_{i j}+$ orig $_{i j}+\operatorname{breed}_{i j}+\operatorname{pulm}_{i j}+\operatorname{diges}_{i j}+\beta \operatorname{Cov}_{i j}+s_{i}$

Lim.: $y_{i j}=$ cont $_{i j}+$ calv $_{i j}+$ orig $_{i j}+\operatorname{manag}_{i j}+\beta \operatorname{Cov}_{i j}+s_{i}$

$y_{i j}$ was the performance of the $j$ th male progeny of the $i$ th sire.

In the study of the sire step 2 selection effect, sire performances were analysed in an animal model (a) with an age-contemporary group (cont). In the Charolais breed, pre-test environment (pre-test) fixed effects were added. A regression on final age $(\beta$ Age $)$ was performed for both breeds: 
Table III. Effect of the selection of sires on the genetic parameters of progeny traits in the Limousine breed.

\begin{tabular}{|c|c|c|c|c|c|c|}
\hline & & & LW & LM & $\mathrm{DP}$ & CF \\
\hline Sire traits & $\begin{array}{c}\text { FW } \\
\text { FE } \\
\text { LM } \\
\text { LS }\end{array}$ & & $\begin{array}{l}0.68 \\
0.23 \\
0.03 \\
0.34\end{array}$ & $\begin{array}{r}0.29 \\
0.05 \\
0.80 \\
-0.64\end{array}$ & $\begin{array}{r}+0.01 \\
0.17 \\
0.29 \\
-0.21\end{array}$ & $\begin{array}{l}-0.09 \\
-0.25 \\
-0.11 \\
-0.02\end{array}$ \\
\hline & LW & $\begin{array}{c}S+P \\
P_{a} \\
P_{e 2} \\
P_{e 1}\end{array}$ & $\begin{array}{l}0.24 \\
0.24 \\
0.17 \\
0.19\end{array}$ & $\begin{array}{l}0.28 \\
0.31 \\
0.13 \\
0.26\end{array}$ & $\begin{array}{l}-0.19 \\
-0.19 \\
-0.27 \\
-0.21\end{array}$ & $\begin{array}{l}0.29 \\
0.29 \\
0.42 \\
0.37\end{array}$ \\
\hline $\begin{array}{l}\text { Progeny } \\
\text { traits }\end{array}$ & LM & $\begin{array}{c}S+P \\
P_{a} \\
P_{e 2} \\
P_{e 1}\end{array}$ & & $\begin{array}{l}0.25 \\
0.25 \\
0.23 \\
0.25\end{array}$ & $\begin{array}{l}0.23 \\
0.23 \\
0.23 \\
0.23\end{array}$ & $\begin{array}{l}0.19 \\
0.20 \\
0.23 \\
0.20\end{array}$ \\
\hline & DP & $\begin{array}{c}S+P \\
P_{a} \\
P_{e 2} \\
P_{e 1}\end{array}$ & & & $\begin{array}{l}0.51 \\
0.51 \\
0.51 \\
0.51\end{array}$ & $\begin{array}{l}-0.34 \\
-0.34 \\
-0.33 \\
-0.34\end{array}$ \\
\hline & $\mathrm{CF}$ & $\begin{array}{c}S+P \\
P_{a} \\
P_{e 2} \\
P_{e 1}\end{array}$ & & & & $\begin{array}{l}0.44 \\
0.44 \\
0.43 \\
0.44\end{array}$ \\
\hline
\end{tabular}

FW: final weight; LW: age-adjusted live weight; FE: feed efficiency; LM: live muscling score; LS: Live skeletal frame score DP: dressing percentage; CF: carcass fatness score. Sire traits section: genetic correlations between sire and progeny traits.

Progeny trait section: first line: $S+P$, progeny and performance tests used simultaneously for estimating sound genetic parameters $\left(h^{2}\right.$ and $r_{g}$ considered free of sire selection effect); second line: $P_{a}$, progeny test used alone for estimating apparent genetic parameters $\left(h_{a}^{2}\right.$ and $r_{a g}$; potentially biased); lower lines: genetic parameters that were expected to be observed $\left(h_{e}^{2}\right.$ and $\left.r_{e g}\right)$ as a consequence of sire selection step 2 $\left(P_{e 2}\right)$ or step $1\left(P_{e 1}\right)$.

In the diagonal: heritabilities $\left(h^{2}\right)$; above the diagonal: genetic correlations $\left(r_{g}\right)$.

Ch.: $y_{i}=$ cont $_{i}+$ pre-test $_{i}+\beta$ Age $_{i}+a_{i}$

Lim.: $y_{i}=$ cont $_{i}+\beta$ Age $_{i}+a_{i}$

$Y_{i}$ was the performance of the $i$ th sire.

\subsubsection{Methods}

The statistical analyses were conducted separately in both breeds. General statistics were calculated using SAS procedures.

Genetic and phenotypic variance and covariance components of the progeny performances were estimated applying the restricted estimation of maximum 
likelihood (REML) method in a multi-trait (nine traits) analysis for each breed (VCE3.2 Package, Groeneveld [11]). These components allowed the elaboration of phenotypic correlations $\left(r_{p}\right)$ and genetic parameters, heritabilities and genetic correlations $\left(h_{a}^{2}\right.$ and $\left.r_{a g}\right)$.

In the study of the sire selection effect, the variance and covariance components among and between sire performances and progeny traits were estimated in a multi-trait analysis (four progeny traits (LW, LM, DP, CF) with or without three or four sire traits (FW, LM, FE and, in the Limousin analysis, LS) by the REML method using VCE4.2 of Groeneveld [11].

\section{RESULTS AND DISCUSSION}

\subsection{Means and phenotypic variability (table $I$ )}

In the Limousin breed, the variability of initial weight was especially high $(\mathrm{SD}=54 \mathrm{~kg}$ and $\mathrm{CV}=15 \%)$. The variability of the corresponding trait among the Charolais crossbred calves was moderate $(\mathrm{SD}=24 \mathrm{~kg}$ and $\mathrm{CV}=$ $11 \%)$. Another analysis using Charolais pure-bred young bulls brought into the progeny test station at weaning, gave high initial weight variability $(\mathrm{SD}=61 \mathrm{~kg}$ and $\mathrm{CV}=15 \%$ ). Raising animals in a common environment might contribute to reducing the differences between animals due to pre-test conditions. In both progeny test stations the variability of live weight around 15 months (LW: CV $=7$ and $9 \%$ in the Charolais and Limousin programmes, respectively) was lower than the initial weight variability (IW: CV $=11$ and $15 \%$, respectively). Fattening progeny in a common environment reduced phenotypic variability among young bulls.

Variability of dressing percentage was low, similar to most of the results in the literature.

Variability of morphology and fatness scores was relatively high with coefficients of variation between 9 and $18 \%$.

The slaughter point criteria was expected to be fixed in both programmes: age in the Limousin and weight in the Charolais programme. This was only partially obtained, especially in the Charolais breed. There were only 4 days for within-year standard deviation $(\mathrm{CV}<1 \%$ ) of slaughter age in the Limousin programme versus $17 \mathrm{~kg}(\mathrm{CV}=3 \%)$ for slaughter weight in the Charolais programme. A fixed age end point is clearly easier to organise than a fixed weight.

\subsection{Effect of selection of sires on the genetic variability of progeny traits (tables II and III)}

\subsubsection{Effect of step 2 selection}

In both programmes, the apparent genetic parameters $\left(h_{a}^{2}\right.$ and $\left.r_{a g}\right)$ estimated without considering the effect of the previous selection of sires were close to the sound ones $\left(h^{2}\right.$ and $r_{g}$ ) estimated jointly with sire performance data (Charolais: table II; Limousine: table III). Apparent heritabilities were only slightly lower (by $0.02-0.03$ ) than correct ones, and genetic correlations 
were within 0.03 of sound ones. These differences depend on the relative change of variance of the traits under selection $(\beta)$, the true heritability of these traits and the magnitude and the sign of the true genetic correlations between these traits and progeny traits. In the present study, the relative reductions of the selection criteria variance, $\beta=\left(\sigma_{I s}^{2}-\sigma_{I}^{2}\right) / \sigma_{I}^{2}$, used for computing the expected genetic parameters were negative (Charolais: - 0.58; Limousine: -0.41 ) since unilateral selection reduced the index variance. Fimland [8] showed that the expected effect of selection for performance is generally minor for heritabilities. For example, with $\beta$ close to -0.55 , and heritability close to 0.30 and 0.40 , he predicted that the remaining genetic variance still represents about $95 \%$ of the initial genetic variance. On the contrary, a substantial modification of the genetic correlation $\left(r_{g j k}\right)$ between two progeny traits may be expected if at least one of these traits has a close genetic correlation with the selection criteria. Usually, with a negative $\beta$ the change in $r_{g j k}$ is negative when $r_{g I j}$ and $r_{g I k}$ have the same sign and the change is positive when $r_{g I j}$ and $r_{g I k}$ have different signs.

According to the reduced effect of selection on genetic variability among progeny, only the genetic parameters estimated without considering the prior sire performance are presented in table $I V$, since the nine progeny traits could be analysed simultaneously.

When the apparent genetic parameters were compared to the expected ones after algebraic correction, no difference was found for live muscling scores, dressing percentages and carcass fatness scores in either programme. Differences for heritabilities were smaller than 0.02 and differences for genetic correlations were smaller than 0.05 . However, the differences for live weight (LW) were larger. For example, the corrected heritability of LW was 0.07 lower than the apparent one in both programmes. Therefore, the formulae used for predicting the effect of selection were not adapted to the real selection procedure for different possible reasons. The genetic correlations between sire and progeny traits used in the algebraic formulae might not have been exactly the true ones as they were estimated with low accuracy (average standard errors equal to 0.10 ). The step 1 selection could not have been taken into account since adding the corresponding amount of information (the whole contemporary group in the herd of origin) made a joint analysis unfeasible as it would have exceeded the capacity of our data processing. This step 1 selection might have influenced the estimated genetic parameters among progeny traits and between sire and progeny traits. The selection procedure (step 2) was certainly not a threshold selection on a selection index combining only three sire performances (LW, LM, FE) because some sires with high indexes were eliminated either for some defects (semen quality, foot and leg soundness, etc.) or for breed standard criteria. Consequently, some bulls with low indexes were kept (figure 1). Contrarily to the estimation of apparent genetic parameters that used information available on progeny of 145 sires, the expected genetic parameters were calculated using the progeny of only 118 sires that were previously tested in the same central station. The remaining 27 sires $(\approx 19 \%)$ had various origins. In the Limousin programme, only 112 sires among the 131 that were progeny tested were previously selected in a performance testing station. Such a loss of information might have influenced the expected genetic correlations among progeny traits. 


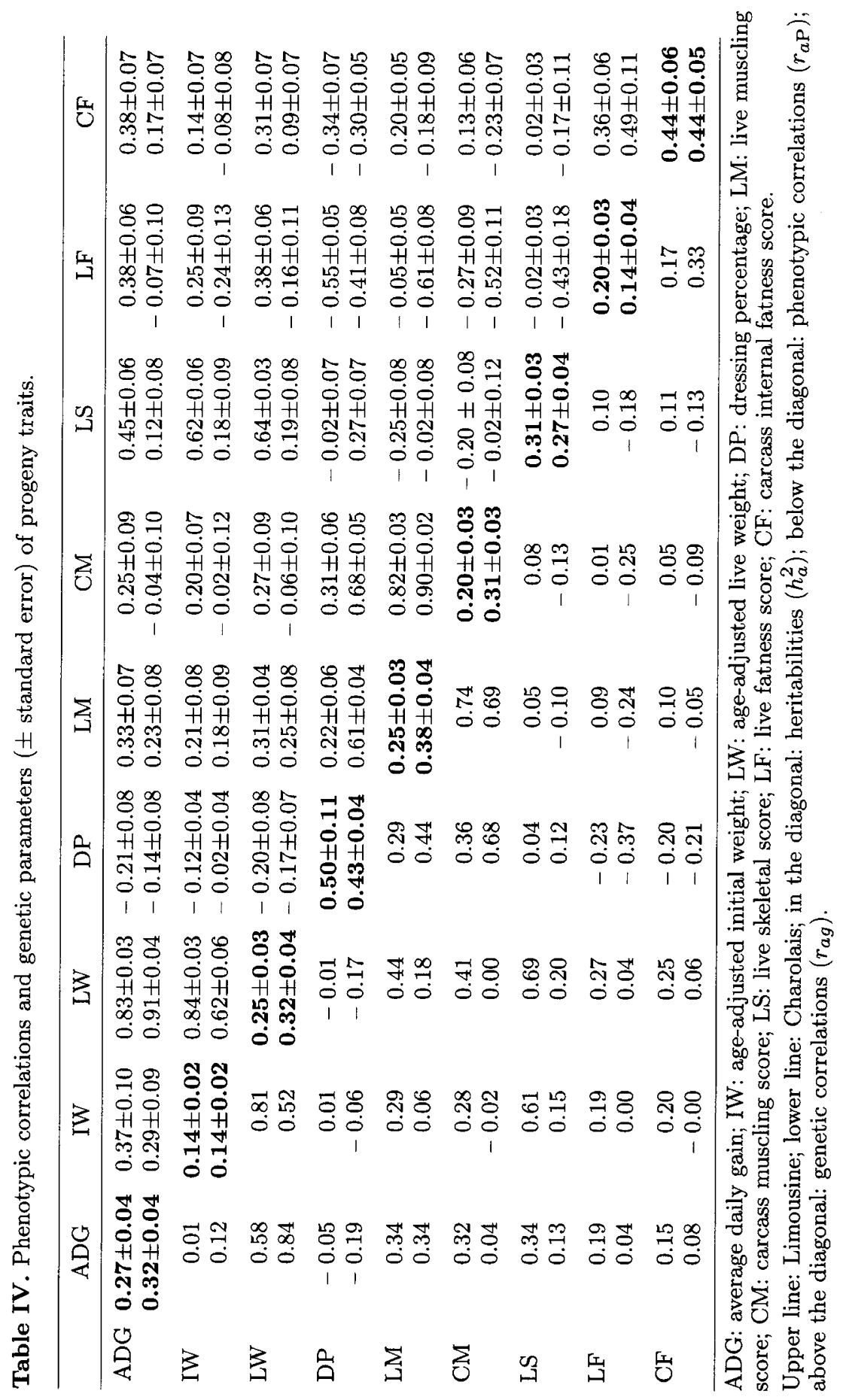




\subsubsection{Effect of step 1 selection}

In both programmes, the impact of step 1 of sire selection was lower than that of step 2 .

In the Charolais programme, the higher differences between the expected and the apparent genetic parameters concerned genetic correlations between live muscling score (LM) and live weight (LW) or dressing percentage (DP).

In the Limousin breed, expected heritability of live weight (LW) and genetic correlations between LW and live muscling score (LM) or carcass fatness score (CF) were slightly different from the apparent ones.

Nevertheless, in both breeds these differences were not significant considering standard errors of 0.04 and 0.07 for heritabilities and genetic correlations, respectively, as shown in table $I V$.

Moreover, genetic correlations between progeny and sire weaning traits were, however, certainly lower, in absolute value, than those between progeny traits and 16-month-old sire traits measured in the central station that we used for predicting the impact of step 1 selection.

As a conclusion, sire selection at weaning should only have minor effects on genetic parameters among progeny performance traits measured at central and progeny test stations.

\subsection{Heritability coefficients $\left(h^{2}\right)$}

Estimates of heritabilities and their standard errors are given in the diagonal of table IV (bold type).

In both breeds, heritabilities for the same traits were close to each other, in spite of a shorter pre-test adaptation period in the Limousin than in the Charolais programme, except for the muscling scores (LM, CM). They were accurately estimated, with low standard errors.

\subsubsection{Growth traits}

Heritabilities of weight at the beginning of the progeny testing (IW) were lower $\left(h^{2}=0.14\right)$ than those of the other post-weaning growth traits $\left(h^{2} \approx\right.$ $0.30)$. This increase in heritability was due to a marked reduction in environmental variability, relative to the mean, while genetic variability remained roughly constant with a coefficient of genetic variation of $5-7 \%$. The high environmental variability of initial weight of Charolais dairy crossbred calves might have been due to health problems in the nursery prior to the test as a consequence of concentrating numerous calves from many herds. The high environmental variability of initial weight of Limousin calves was certainly due to large differences between pre-test environments, late entrance and short adaptation periods. In the Blond d'Aquitaine breed, Renand et al. [30] also found a heritability lower for initial weight $\left(h^{2}=0.10\right)$ than for the weight $\left(h^{2}=0.24\right)$ of 500-day pure-bred suckling calves. A lower heritability of weaning weight of suckling calves compared to post-weaning growth traits was, also, generally observed in the literature $[2,15,33]$. This may partly explain the low heritability of initial weight that was recorded only 1 month after weaning in the Limousin testing programme. 
The heritability coefficients of post-weaning growth traits - average daily gain (ADG) and final live weight (LW) - were slightly higher in the Charolais breed $\left(h^{2} \approx 0.32\right)$ than in the Limousin breed $\left(h^{2} \approx 0.26\right)$. Limousin coefficients were similar to the coefficients found in Blond d'Aquitaine by Renand et al. [30]: $h^{2} \approx 0.26$. Mohuiddin [21] also reviewed higher heritabilities for growth traits in the Charolais than in the Limousin breed. The heritabilities in the Charolais breed were close to those of 18-month-old Charolais heifers in the testing station $\left(h^{2} \approx 0.33\right.$ final weight) presented by Menissier [18] and by Renand et al. [31] for progeny-tested Charolais bulls in a divergent selection experiment $\left(h^{2}=0.27\right.$ average daily gain). Many genetic parameters for growth traits have already been estimated $[15,21]$. Most of these analyses present moderate to high heritabilities for growth traits.

\subsubsection{Morphology scores}

Morphology scores recorded during the month before slaughter also exhibited medium heritabilities. In both breeds, heritability of carcass muscling score (CM) was slightly lower than those of the live muscling score (LM) $(0.20$ and 0.25 versus 0.31 and 0.38 for $\mathrm{CM}$ and $\mathrm{LM}$ in the Limousin and the Charolais breed, respectively). Renand et al. [30] obtained similar heritabilities for both scores $\left(h_{\mathrm{LM}}^{2}=0.38\right.$ versus $\left.h_{\mathrm{CM}}^{2}=0.36\right)$ in the Blond d'Aquitaine breed. On the contrary, Dijkstra et al. [7] found a higher heritability for the carcass muscling score. In the literature, muscularity of live animals is assessed either by visual scores, body measurements or scanning measurements of the rib eye depth or area. Visual scores, body and scanning measurements are usually moderately heritable $\left(h^{2} \approx 0.28[2,21]\right)$. The heritabilities of carcass measurements are slightly higher $\left(h^{2} \approx 0.41[15] ; h^{2}=0.73[6]\right)$.

Heritabilities of live skeletal frame scores (LS) in both breeds were moderate $\left(h^{2} \approx 0.29\right)$. These coefficients were close to the heritability estimated for LS by Renand et al. [30] in Blond d'Aquitaine. Skeletal frame scores are less frequently studied than muscular development. Heritability coefficients of both morphology scores of Limousin and Charolais females were estimated by Sapa et al. [33] for 18-month-old heifers recorded in progeny testing stations. They found higher heritabilities as compared to the present study: $h^{2}=0.52$ and 0.43 , respectively, for muscling scores in the Limousin and Charolais breeds and $h^{2}=0.48$ and 0.37 for skeletal frame scores. Chavaz [5] also observed that heritabilities of height at wither and length score of dual purpose breed heifers are higher than muscling and width scores.

\subsubsection{Fatness traits}

In both breeds, heritabilities of live fat scores were lower $\left(h^{2} \approx 0.17\right)$ than those of carcass fat scores $\left(h^{2}=0.44\right)$. These scores did not represent the same trait. Live fatness score was visual and evaluated subcutaneous fat thickness. Internal carcass fatness was a visual score of the amount of channel fat. The genetic variability of live fat score was generally lower than that of carcass fat. Renand et al. [30] estimated similar and moderate heritabilities for live fat covering and internal fatness scores $\left(h^{2} \approx 0.30\right)$ in the Blond d'Aquitaine breed. In the literature, it appears that heritability of live visual or handling appraisal 
of the subcutaneous fat thickness is lower (0.05 [22], 0.27 [7]) than its ultrasound or carcass measurements ([21]: from 0.21 to 0.57 ). Genetic variability of carcass fatness is therefore better estimated when scoring carcasses than scoring live animals. All of these fatness traits should be genetically improved by direct selection although there is some difficulty in measuring them accurately on a large scale.

\subsubsection{Dressing percentage (DP)}

In both breeds, heritability of dressing percentage was higher than those estimates for growth and conformation. Genetic variability of carcass yield was slightly higher in the Limousin than in the Charolais breed $\left(h^{2}=0.50\right.$ and $h^{2}=0.43$, respectively). Fixed weight at slaughter in the Charolais breed might have contributed to a decreased DP variability. However, in a literature review, Koots et al. [15] obtained similar average heritabilities for DP at fixed weight or fixed age end points. Renand et al. [30] estimated a moderate heritability for DP $(0.24 \pm 0.12)$ among Blond d'Aquitaine young bulls slaughtered at a fixed age of 529 days. In the literature, heritabilities for carcass yield are moderate (0.18: [38]) to very high (0.72: [3]).

All of the analysed growth, morphology and carcass composition performances had moderate heritabilities. They can, therefore, be improved through genetic selection. Nevertheless, the efficiency of selection may be influenced by the genetic correlations between the selected traits and the other ones.

\subsection{Phenotypic and genetic correlation coefficients}

The estimates of phenotypic and genetic correlation ( \pm standard errors) coefficients are reported in table $I V$. Most of the correlation standard errors estimated with VCE were close to 0.08. However, approximate standard errors of correlations [34] assuming a balanced scheme were about twice those given by VCE.

\subsubsection{Correlations among growth traits}

The genetic correlations among growth traits estimated in this study, were close to those reported by Koots et al. [16]. Most of them were highly positive and favourable. The genetic correlations were more pronounced than the phenotypic ones, whereas, in the literature, the genetic and phenotypic correlations among post-weaning growth traits are, usually, similar [16]. In our study and in both breeds, average daily gain in the station was phenotypically independent of initial weight while both growth traits were genetically linked $\left(r_{g} \approx 0.33\right)$. These results show that the correlation between pre-test and test environment effects was probably slightly negative. There was certainly some compensatory growth during the test period. In the Charolais progeny, final live weight (LW) was more closely related to daily gain $\left(r_{p}=0.84\right.$ and $\left.r_{g}=0.91\right)$ than to initial weight $\left(r_{p}=0.52\right.$ and $\left.r_{g}=0.62\right)$. Both traits were equivalently genetically related to final weight in the Limousin progeny $\left(r_{g}=0.83\right.$ and 0.84$)$. The same has been observed by Renand et al. [30] in the Blond d'Aquitaine breed where progeny suckling calves entered the station after weaning. The 
longer the length of the test period compared to the initial age, the more final weight was influenced by daily gain measured during the test.

\subsubsection{Correlations between growth traits and dressing percentage (DP)}

In the Limousin breed, growth traits and DP were phenotypically independent. In the Charolais breed, initial weight (IW) and DP were phenotypically independent. On the contrary, the phenotypic correlations between final live weight $(\mathrm{LW})$ or average daily gain (ADG) and DP were slightly negative. Such very low phenotypic relations between DP and growth traits have already been observed $[16,30]$.

Genetic correlations between DP and growth traits were all negative $(-0.02$ to -0.21 ), then unfavourable, especially in the Limousin breed. Nevertheless, as previously observed by Koots et al. [16], the genetic correlations estimated between age-adjusted carcass weight and live growth traits were positive. In the Limousin and Charolais breeds genetic correlations between age-adjusted carcass weight and final live weight were: $r_{g}=0.93$ and $r_{g}=0.85$, respectively. Carcass weight was improved in spite of the decrease in the DP genetic level when selecting final live weight.

\subsubsection{Correlations among conformation traits}

As for growth traits, most of the genetic correlations among conformation traits were stronger than phenotypic correlations.

In both breeds, the correlations estimated between live and carcass muscling scores were very high $\left(r_{p} \approx 0.70\right.$ and $\left.r_{g} \approx 0.85\right)$ and close to those observed by Renand et al. [30] in the Blond d'Aquitaine breed $\left(r_{g}=0.76\right)$. Carcass muscling score (CM) may be easily improved through selection for live muscling score (LM).

In both breeds, muscling (CM, LM) and skeletal (LS) development were phenotypically independent. Corresponding genetic correlations were null and moderately negative in the Charolais and Limousin breeds, respectively. In the literature, studies on the relation between muscularity and frame development are scarce as scoring LS is not usual. In the Canadian Limousin breed, Miglior et al. [19] estimated a positive genetic correlation between LS and LM $\left(r_{g}=0.55\right)$. In the Blond d'Aquitaine breed, at a constant slaughter age, Renand et al. [30] estimated a positive genetic correlation between LS and CM $\left(r_{g}=0.50\right)$ while LS and LM were genetically independent $\left(r_{g}=-0.02\right)$.

\subsubsection{Correlations among fatness traits}

As observed by Renand et al. [30] in the Blond d'Aquitaine breed, phenotypic and genetic correlations between live fatness covering score (LF) and carcass fatness score (CF) were moderate even if positive in the Charolais and Limousin breeds. As already suggested, LF and CF did not represent the same traits. Subcutaneous fat deposition may not use the same physiological mechanisms as channel fat deposition or marbling settlement $[2,12,36]$. These low correlations might certainly also be due to errors when scoring fatness on live animals or 
carcasses. In the literature, higher genetic correlations can be found among different fatness carcass measurements (subcutaneous fat thickness, internal fatness score, marbling score, etc.) $[14,17,30]$.

\subsubsection{Correlations between growth traits and morphology scores}

In the Limousin breed, phenotypic and genetic correlations between growth traits (ADG, IW, LW) and live or carcass morphology scores (LM, CM, LS) were all positive. They were higher with the skeletal development score (LS) than with muscling scores (CM and LM). Hence, in this breed, live growth was mainly linked to skeletal development. According to the genetic independence between LS and dressing percentage (DP), the moderate and positive correlations between DP and muscling scores (LM, CM) and the moderate but negative correlations between DP and the growth traits (IW, $\mathrm{LW}, \mathrm{ADG})$, carcass weight $(\mathrm{CW})$ was more related to skeletal frame rather than muscling. Further analyses confirmed this assessment $\left(r_{g}=0.60\right.$ between $\mathrm{CW}$ and LS and, $r_{g} \approx 0.41$ between $\mathrm{CW}$ and LM or $\mathrm{CM}$ ).

In the Charolais breed, genetic and phenotypic correlations between growth performance and morphology traits were lower than in the Limousin breed. The highest genetic correlations were observed between ADG or LW and live muscling score (LM) (0.23 and 0.25 , respectively). Growth traits and carcass muscling score (CM) were independent. Due to the higher genetic correlations between DP and muscling scores (LM, CM: 0.60) than between DP and LS (0.27), carcass weight (CW) was more related to muscling development rather than skeletal development. This was also confirmed by further analyses $\left(r_{g}=0.20\right.$ between CW and LS and, $r_{g} \approx 0.58$ between CW and LM).

The genetic relation between growth and morphology might also depend on the objective of the selection programme. In the Limousin breed, most of the production consisted of pure-bred young calves. Therefore, large frame sires were preferentially selected. On the contrary, in the Charolais programme, compact sires (high muscling) were selected to procreate crossbred young bulls. Breed and fixed final point could also influence the relation between morphology and growth rate [27]. In the literature [16, 19, 21, 36, 37], genetic correlations between muscle development and growth (especially carcass growth) vary: from $-0.66[21]$ to 0.90 [19]. Estimation of the correlations between skeletal development and growth are scarce (0.23 with ADG and 0.34 with weight [19]).

\subsubsection{Correlations between fatness traits and growth traits, morphology scores and dressing percentage}

The two breeds presented the same genetic relation between fatness traits (LF, CF) and dressing percentage (DP). Genetic correlations were negative, then, favourable. They were closer with LF $\left(r_{g} \approx-0.48\right)$ than with CF $\left(r_{g} \approx-0.32\right)$.

In both breeds, phenotypic correlations between fatness and growth traits or morphology scores were low. In the Limousin breed, at a constant age, those with live or carcass fatness scores were all lowly positive: $r_{p} \approx 0.15$ on average. In the Charolais breed, at a constant weight, fatness scores were almost independent of growth traits: $r_{p} \approx 0.05$ and lowly opposed with morphology scores: $r_{p} \approx-0.15$. 
Genetic correlations of live fatness scores with other traits differed from genetic correlations of carcass fatness with these other traits. On average, fatness had a positive genetic correlation with growth traits in the Limousin breed: $r_{g} \approx 0.36$, from 0.31 to 0.38 , then unfavourable. Heavier Limousin young bulls at the end of the test tended to have higher backfat thickness and larger amounts of channel fat. In the Charolais breed, these genetic correlations were around zero: $r_{g} \approx 0.01$, from -0.16 to 0.17 .

In contrast, the genetic correlations of fatness scores with morphology scores were around zero in the Limousin breed: $r_{g} \approx 0.00$, from -0.27 to 0.20 , while they were all negative, favourable, in the Charolais breed: $r_{g} \approx-0.36$, from -0.61 to -0.17 . Muscled or large frame Charolais young bulls tended to have lower fatness scores.

In the Blond d'Aquitaine breed, Renand et al. [30] estimated different relations between fatness traits and growth or morphology traits. The genetic correlations between carcass fatness and growth traits were slightly positive $\left(r_{g}=0.05\right.$ and 0.21 with AGD and LW, respectively). Carcass fatness (CF) was almost independent of morphology traits $\left(r_{g}=0.12,-0.05\right.$ and 0.16 with LM, CM and LS, respectively).

Genetic type might be the main factor of discrimination of fatness status between breeds. These differences could also be due to a final fixed point that might influence the degree of maturity at slaughter and, therefore, fat deposition intensity. Renand [27] in a literature review found lower genetic correlations between fat thickness and growth rate (GR) or rib eye area (REA) at a fixed weight final point $(-0.36$ : GR; -0.38 : REA) than at a fixed age final point $(0.31$ : GR; -0.11 REA). These tendencies were similar to those we observed (Charolais: fixed weight; Limousin and Blond d'Aquitaine: fixed age).

In the literature, genetic correlations between fatness and muscling are usually negative: from -0.04 [17] to -0.47 [36]. In contrast, genetic correlations estimated between fatness and growth traits are usually positive [21].

\section{CONCLUSION}

The prior selection of sires did not have an important effect on the estimation of genetic parameters, in spite of the expected impact calculated on some parameters (tables $I I$ and $I I I)$. The estimated heritability coefficients for growth traits, morphology and carcass fatness scores showed the same tendencies in the Charolais and the Limousin breeds. Most of them were moderate (from 0.20 to 0.40 ). Dressing percentage and internal fat score showed higher heritabilities $(\approx 0.40)$.

Breeds did not show the same genetic relationships between traits, probably due to the genetic background and the breed objective. Nevertheless, in both breeds, due to high genetic correlations, carcass weight and muscularity can be easily improved via genetic selection combining live growth rate and live muscle development score of the progeny. In contrast, carcass composition, such as carcass fatness score, was poorly or moderately correlated with live performances. In France, sire indices are published with a corresponding coefficient of determination (CD) and only sires with a CD higher than 0.50 are allowed to be used for artificial insemination [1]. The CD of a progenytested sire depends on the heritabilities and the amount of information available 
for each tested sire and for each reference sire and on the number of sires simultaneously progeny tested [9]. When heritability is 0.40 and ten sires are simultaneously progeny tested with three reference sires, 18 progeny per tested sire and 22 per reference sire have to be tested to reach a CD equal to 0.50 [1]. Only progeny testing station allows one to reach such an accuracy with such a number of progeny. Since the environment and the slaughter conditions are under control, heritabilities may be higher and performances can be measured more precisely as compared to farm or slaughterhouse performance recordings. Selection intensity of AI bulls based on performance of their progeny controlled in the station is limited by the restricted number of sires that can, however, be progeny tested per year. In these selection programmes, the objective of progeny testing is principally to obtain accurate breeding value estimates of slaughter performances while the objective of performance testing is principally to obtain genetic superiority of live traits. The genetic superiority of these sires is expected to be predominantly acquired during the previous steps of sire selection especially at the end of their own post-weaning performance recording in central test stations (step 2). Whether or not these previous steps are efficient to improve the beef traits of their progeny have to be analysed, estimating the genetic correlations between the sire and their progeny traits.

\section{REFERENCES}

[1] Anonym, Répertoire Français des méthodes et des procédures de contrôle et d'évaluation génétique des reproducteurs ovins et bovins de races allaitantes, Institut de l'élevage, compte rendu no. 2316, Paris, France, 1995.

[2] Arnold J.W., Bertrand J.K., Benyshek L.L., Ludwig C., Estimates of genetic parameters for live animal ultrasound, actual carcass data and growth traits in beef cattle, J. Anim. Sci. 69 (1991) 985-992.

[3] Averdunk G., Woodward B., Sauerer G., Schild H.J., Reinhardt F., Performance test results in relation with progeny tests under station and field conditions for Fleckvieh, in: Korver S., Averdunk G., Andersen B.B. (Eds.), Performance Testing of AI Bulls for Efficiency and Beef Production in Dairy and Dual-purpose Breeds, EAAP Publication, 34, Pudoc, Wageningen, The Netherlands, 1987, pp. 36-44.

[4] Bulmer M.G., The effect of selection on genetic variability, Am. Nat. 105 (1971) 201-211.

[5] Chavaz J., Relationship between performance test and various progeny traits in the Swiss dual purpose breeds, in: Korver S., Averdunk G., Andersen B.B. (Eds.), Performance Testing of AI Bulls for Efficiency and Beef Production in Dairy and Dual-purpose Breeds, EAAP Publication, 34, Pudoc, Wageningen The Netherlands, 1987 , pp. $52-58$.

[6] Cundiff L.V., Chambrers D., Stephens D.F., Willham R.L., Genetic analysis of some growth and carcass traits in beef cattle, J. Anim. Sci. 23 (1964) 1133-1138.

[7] Dijkstra J., Oldenbroek J.K., Korver S., Van Der Werf J.H.J., Breeding for veal and beef production in Dutch red and white Cattle, Livest. Prod. Sci. 25 (1990) 183-198.

[8] Fimland E.A., The effect of selection on additive genetic parameters, $\mathrm{Z}$. Tierzüchtg. Züchtgsbiol. 96 (1979) 120-134.

[9] Foulley J.L., Clerget-Darpoux F., Progeny group size for evaluating natural service bulls using AI reference sires. Ann. Génét. Sél. Anim. 10 (1978) 541-556.

[10] Groeneveld E., REML VCE, Version 3.2, User's Guide, Federal Research Center of Agriculture, Mariensee, Germany, 1996. 
[11] Groeneveld E., REML VCE, Version 4.2, User's Guide, Federal Research Center of Agriculture, Mariensee, Germany, 1998.

[12] Hirooka H., Groen A.F., Matsumoto M., Genetic parameters for growth and carcass traits in Japanese Brown cattle estimated from field records, J. Anim. Sci. 74 (1996) 2112-2116.

[13] Journaux L., Estimation conjointe des composantes de la variance en contrôle individuel et en contrôle de descendance par la méthode du Maximum de Vraisemblance Restreinte, Report, 1991, 45 p.

[14] Koch R.M., Selection in beef cattle. III - Correlated response of carcass traits to selection for weaning, yearling weight and muscling score in cattle, J. Anim. Sci. 47 (1978) 142-150.

[15] Koots K.R., Gibson J.P., Smith C., Wilton J.W., Analyses of published genetic parameter estimates for beef production traits. I - Heritability, Anim. Breed. Abstr. 62 (1995) 309.

[16] Koots K.R., Gibson J.P., Smith C., Wilton J.W., Analyses of published genetic parameter estimates for beef production traits. II - Phenotypic and genetic correlations, Anim. Breed. Abstr. 62 (1995) 825.

[17] Lamb M.A., Robison O.W., Tess M.W., Genetic parameters for carcass traits in Hereford bulls, J. Anim. Sci. 68 (1990) 64-69.

[18] Ménissier F., Comments on optimization of cattle breeding schemes: beef breeds for suckling herds: a review, Ann. Génét. Sél. Anim. 8 (1976) 71-87.

[19] Miglior F., Kemp R.A., Burnside E.B., Genetic parameter estimates of conformation and performance traits in station-tested Limousin bulls, Can. J. Anim. Sci. 74 (1994) 379-381.

[20] Minvielle F., Principes d'amélioration génétique des animaux, Les Presses de l'Université Laval, INRA, 1990, 232 p.

[21] Mohiuddin G., Estimates of genetic and phenotypic parameters of some performance traits in beef cattle, Anim. Breed. Abstr. 61 (1993) 495-522.

[22] Oldenbroek J.K., Laurijsen H.A.J., ten Napel J., Relationship between performance test and progeny test for veal and beef production in Black and White dairy cattle, in: Korver S., Averdunk G., Andersen B.B. (Eds.), Performance Testing of AI Bulls for Efficiency and Beef Production in Dairy and Dual-purpose Breeds, EAAP Publication, 34, Pudoc, Wageningen The Netherlands, 1987, pp. 45-51.

[23] Ollivier L., Derrien A., Une méthode générale d'estimation des paramètres génétiques dans un échantillon sélectionné, avec une application à une sélection sur un indice à trois caractères, Ann. Génét. Sél. Anim. 13 (1981) 231-292.

[24] Pearson K., On the influence of natural selection on the variability and correlation of organs, R. Soc. London. Phil. Trans. A 200 (1903) 1-66.

[25] Renand G., Genetic parameters of French beef Breeds used in crossbreeding for young bull production. I - Live performance, Génét. Sél. Evol. (1985) 17 (1985) 153-170.

[26] Renand G., Genetic parameters of French beef breeds used in crossbreeding for young bull production. II - Slaughter performance, Génét. Sél. Evol. 17 (1985) $265-282$.

[27] Renand G., Genetic determinism of carcass and meat quality in cattle, 3rd World Congress on Sheep and Beef Cattle Breeding 1, INRA publ., Paris, 1998, pp. 381-395.

[28] Renand G., Mise en place du Vachotron II, Séminaire Planification Expérimentale en Génétique Animale à St Martin de Ré, INRA, Paris, 1996, pp. 123-134.

[29] Renand G., Gaillard J., Variability of direct genetic effects on growth and slaughter performance in the Charolais breed for production of young beef bulls, Proc. 2nd World Congr. Genet. Applied. Livest. Prod., Madrid, 1982, pp. 356-362. 
[30] Renand G., Gaillard J., Ménissier F., Genetic parameters for growth and slaughter traits of purebred Blond d'Aquitaine young bulls, 37th Annual Meeting of the EAAP, Budapest, Hungary, 1986.

[31] Renand G., Fouilloux M.N., Ménissier F., Genetic improvement of beef production traits by performance testing beef bulls in France, Proc. 6th World Congr. Genet. Applied. Livest. Prod., Armidale 23 (1998) 77-80.

[32] Robertson A., The effect of selection on the estimation of genetic parameters, Z. Tierz. Zuechtungsbiol. 94 (1977) 131-135.

[33] Sapa J., Ménissier F., Renand G., Liboriussen T., Courteix S., Duclaud P.J., Variabilité génétique la croissance et de la fertilité de génisses de races à viande Françaises spécialisées, 41st Annual Meeting of the European Association for Animal Production, Toulouse, France, 1990.

[34] Tallis G.M., Sampling errors of genetic correlation coefficients calculated from analyses of variance and covariance, Aust. J. Stat. 1 (1959) 35-43.

[35] Van der Werf J.H.J, de Boer I.J.M, Estimation of additive genetic variance when base population are selected, J. Anim. Sci. 68 (1990) 3124-3132.

[36] Wilson L.L., Mc Curley J.R., Ziegler J.H., Watkins J.L., Genetic parameters of live and carcass characters from progeny of Polled Hereford and Angus-Holstein cows, J. Anim. Sci. 43 (1976) 569-576.

[37] Wilson D.E., Willham R.L., Northcutt S.L., Rouse G.H., Genetic parameters for carcass traits estimated from Angus field records, J. Anim. Sci. 71 (1993) $2365-2370$.

[38] Woodward B.W., Pollak E.J., Quaas R.L., Parameter estimation for carcass traits including growth information of Simmental beef cattle using Restricted Maximum Likelihood with a multiple-trait model, J. Anim. Sci. 70 (1992) 1098-1109.

\section{APPENDIX: Effect of the previous selection of sires on the genetic variability of progeny traits}

a) If no sire selection occurred, progeny performance trait $(P)$ and its variance $\sigma_{P}^{2}$ could be broken down into their identified environmental $(F)$, genetic $(g)$ and residual $(e)$ components as follow:

$$
P=\left\{\begin{array}{l}
=F+g+e \\
=F+s+m+\phi+e \\
=F+s+E+e \\
=F+\frac{1}{2} g_{s}+\frac{1}{2} g_{M}+\phi+e
\end{array}\right.
$$

and

$$
\sigma_{P}^{2}=\left\{\begin{array}{l}
=\sigma_{g}^{2}+\sigma_{e}^{2} \\
=\sigma_{s}^{2}+\sigma_{m}^{2}+\sigma_{\phi}^{2}+\sigma_{e}^{2} \\
=\sigma_{s}^{2}+\sigma_{E}^{2}+\sigma_{e}^{2} \\
=\frac{1}{4} \sigma_{g_{s}}^{2}+\sigma_{E}^{2}+\sigma_{e}^{2}
\end{array}\right.
$$

where $P$ is the progeny performance, $F$ is the fixed effect, $g$ is the direct genetic additive value, $s$ is the 'paternal' component of the genetic additive value $g$, 
$m$ is the 'maternal' component of the genetic additive value $g, g_{s}$ is the direct genetic additive value of the sire $\left(\frac{1}{2} g_{S}=s\right), g_{M}$ is the direct genetic additive value of the dam $\left(\frac{1}{2} g_{M}=m\right), \phi$ is Mendelian sampling $E=m+\phi, e$ is the residual. All the covariances between $s$ (or $m$ ), $\phi$ and $e$ were considered null. As sires and dams were random mated, the covariance between $s$ and $m$ was null.

Moreover, if no selection occurred then $\sigma_{g}^{2}=\sigma_{g_{s}}^{2}$, consequently $\sigma_{s}^{2}=\frac{1}{4} \sigma_{g}^{2}$ and $\sigma_{E}^{2}=\frac{3}{4} \sigma_{g}^{2}$.

Then, the heritability was $h^{2}=\frac{\sigma_{g}^{2}}{\sigma_{g}^{2}+\sigma_{e}^{2}}=\frac{4 \sigma_{s}^{2}}{\sigma_{s}^{2}+\sigma_{E}^{2}+\sigma_{e}^{2}}$,

and the genetic correlation between two progeny traits, $j$ and $k$, was

$$
r_{g_{j k}}=\frac{\operatorname{cov}\left(g_{j}, g_{k}\right)}{\sigma_{g_{j}}} * \sigma_{g_{k}}
$$

a) If sire selection occurred, equations (1) and (2) were transformed as follow: parameters modified by the selection were quoted with a ' $s$ ' subscript.

$$
P=\left\{\begin{array}{l}
=F+g_{s}+e \\
=F+s_{s}+m+\phi+e \\
=F+s_{s}+E+e \\
=F+\frac{1}{2} g_{s_{s}}+\frac{1}{2} g_{M}+\phi+e
\end{array}\right.
$$

and

$$
\sigma_{P_{s}}^{2}=\left\{\begin{array}{l}
=\sigma_{g_{s}}^{2}+\sigma_{e}^{2} \\
=\sigma_{s_{s}}^{2}+\sigma_{m}^{2}+\sigma_{\phi}^{2}+\sigma_{e}^{2} \\
=\sigma_{s_{s}}^{2}+\sigma_{E}^{2}+\sigma_{e}^{2} \\
=\frac{1}{4} \sigma_{s_{s}}^{2}+\sigma_{E}^{2}+\sigma_{e}^{2}
\end{array}\right.
$$

As sire selection occurred, $\sigma_{E}^{2}$ was not changed: $\sigma_{E}^{2}=\frac{3}{4} \sigma_{g}^{2} ;$ unlike $\sigma_{s_{s}}^{2}=\frac{1}{4} \sigma_{g_{s}}^{2}$ and consequently, the apparent heritability was:

$$
h_{s}^{2}=\frac{\sigma_{g_{s}}^{2}}{\sigma_{P_{s}}^{2}}=\frac{\sigma_{g_{s}}^{2}}{\sigma_{s_{s}}^{2}+\sigma_{E}^{2}+\sigma_{e}^{2}}=\frac{\sigma_{g_{s}}^{2}}{\frac{1}{4} \sigma_{g_{s}}^{2}+\frac{3}{4} \sigma_{g}^{2}+\sigma_{e}^{2}}=\frac{\sigma_{g_{s}}^{2}}{\frac{1}{4}\left(\sigma_{g_{s}}^{2}+\sigma_{g}^{2}\left(\frac{4-h^{2}}{h^{2}}\right)\right)}
$$

and the apparent genetic correlation between two progeny traits, $j$ and $k$, was:

$$
r_{s g_{j k}}=\frac{\operatorname{cov}\left(g_{j s}, g_{k s}\right)}{\sigma_{g_{j s}}{ }^{*} \sigma_{g_{k s}}}
$$


According to Renand [27] and Ollivier et al. [22], the matrix of variances covariances in the non-selected population was:

$$
V=\left[\begin{array}{cc}
\sigma_{I}^{2} & V_{I j} \\
\operatorname{sym} & V_{j j}
\end{array}\right]
$$

$\sigma_{I}^{2}$ is variance of the selection criterion (a phenotypic index: $I=\sum_{i} b_{i} P_{i}$ ); $V_{j j}$ is the variance of progeny trait $j ; V_{I j}$ is the covariance between $I$ and $j$.

In the selected population, the corresponding matrix was:

$$
V_{s}=\left[\begin{array}{cc}
\sigma_{I_{s}}^{2} & V_{I j_{s}} \\
\operatorname{sym} & V_{j j_{s}}
\end{array}\right]=\left[\begin{array}{cc}
\sigma_{I_{s}}^{2} & \sigma_{I_{s}}^{I} \sigma_{I}^{-2} V_{I j} \\
\operatorname{sym} & V_{j j}-V_{j I} \sigma_{I}^{-2}\left(\sigma^{2}-I-\sigma_{I_{s}}^{2}\right) \sigma_{I}^{-2} V_{I j}
\end{array}\right]
$$

The relative reduction of the index variance due to the selection of sires was:

$$
\beta=\frac{\sigma_{I_{s}}^{2}-\sigma_{I}^{2}}{\sigma_{I}^{2}}
$$

Consequently, the observed index variance in the selected population (of sires) was $\sigma_{I_{s}}^{2}=(\beta+1) \sigma_{I}^{2}$

Then, the expected variance of a progeny trait $j$ was:

$$
\begin{aligned}
& \sigma_{g_{j s}}^{2}=\sigma_{g_{j}}^{2}-\sigma_{g_{j}, I} \sigma_{I}^{-2}\left(\sigma_{I}^{2}-\sigma_{I_{s}}^{2}\right) \sigma_{I}^{-2} \sigma_{I, g_{j}} \\
& \sigma_{g_{j s}}^{2}=\sigma_{g_{j}}^{2}+\beta \sigma_{I}^{-2} \sigma_{g_{j}, I}^{2}=\sigma_{g_{j}}^{2}\left(1+\beta \sigma_{I}^{-2} R_{j}^{2}\right)
\end{aligned}
$$

where

$$
\begin{aligned}
\sigma_{g_{j}, I} & =\operatorname{cov}\left(g_{j}, I\right)=\operatorname{cov}\left(g_{j}, \sum_{i} b_{i} P_{i}\right)=\sum_{i} b_{i} \operatorname{cov}\left(g_{j}, P_{i}\right) \\
& =\sum_{i} b_{i} \operatorname{cov}\left(g_{j}, g_{i}\right)=\sum_{i} b_{i} r_{g_{i j}} \sigma_{g_{j}} \sigma_{g_{i}}=\sigma_{g_{j}} \sum_{i} b_{i} r_{g_{i j}} \sigma_{g_{i}}=\sigma_{g_{j}} R_{j}
\end{aligned}
$$

and $R_{j}=\sum_{i} b_{i} r_{g_{i j}} \sigma_{g_{i}}$

The expected sire component of a progeny trait variance $\left(s_{j}\right)$ was:

$$
\begin{aligned}
\sigma_{s_{j s}}^{2} & =\sigma_{s_{j}}^{2}-\sigma_{s_{j}, I} \sigma_{I}^{-2}\left(\sigma_{I}^{2}-\sigma_{I_{s}}^{2}\right) \sigma_{I}^{-2} \sigma_{I, s_{j}} \\
& =\frac{1}{4} \sigma_{g_{j}}^{2}\left(1+\beta \sigma_{I}^{-2} R_{j}^{2}\right)=\frac{1}{4} \sigma_{g_{j s}}^{2}
\end{aligned}
$$

with $R_{s j}=\sum_{i} b_{i} r_{s_{j}, g_{i}} \sigma_{g_{i}}=R_{j}$ as $r_{s_{j}, g_{i}}=\frac{\operatorname{cov}\left(s_{j}, g_{i}\right)}{\sigma_{s_{j}}{ }^{*} \sigma_{g_{i}}}=\frac{\operatorname{cov}\left(2 g_{j}, g_{i}\right)}{2 \sigma_{g_{k}}{ }^{*} \sigma_{g_{i}}}=r_{g_{i j}}$ 
Similarly, the expected covariance among progeny traits $j$ and $k$ was:

$$
\begin{aligned}
\operatorname{cov}_{s}\left(g_{j}, g_{k}\right) & =\operatorname{cov}\left(g_{j}, g_{k}\right)-\operatorname{cov}\left(g_{j}, I\right) \sigma_{I}^{-2}\left(\sigma_{I}^{2}-\sigma_{I_{s}}^{2}\right) \sigma_{I}^{-2} \operatorname{cov}\left(I, g_{k}\right) \\
& =\left[r_{g_{j k}}+\beta \sigma_{I}^{-2} R_{j} R_{k}\right] \sigma_{g_{j}} \sigma_{g_{k}}
\end{aligned}
$$

as $\operatorname{cov}\left(g_{j}, g_{k}\right)=r_{g_{j k}} \sigma_{g_{j}} \sigma_{g_{k}}$ and the expected covariance between the sire index $(I)$ and a progeny trait $(j)$ was:

$$
\begin{aligned}
& \operatorname{cov}_{s}\left(I, g_{j}\right)=\sigma_{I_{s}}^{2} \sigma_{I}^{-2} \operatorname{cov}\left(I, g_{j}\right) \\
& \operatorname{cov}_{s}\left(I, g_{j}\right)=(1+\beta) \sigma_{g_{j}} R_{j}
\end{aligned}
$$

Consequently, the expected heritability of a progeny trait $(j)$ was:

$$
h_{s j}^{2}=\frac{\left(\sigma_{I}^{2}+\beta R_{j}^{2}\right)}{\sigma_{I}^{2}+0.25 \beta R_{j}^{2} h_{j}^{2}} * h_{j}^{2}
$$

as

$$
h_{s j}^{2}=\frac{\sigma_{g_{s j}}^{2}}{\frac{1}{4}\left(\sigma_{g_{s j}}^{2}+\sigma_{g_{j}}^{2}\left(\frac{4-h_{j}^{2}}{h_{j}^{2}}\right)\right)}=\frac{\sigma_{g_{j}}^{2}\left(1+\beta \sigma_{I}^{-2} R_{j}^{2}\right)}{\sigma_{g_{j}}^{2}\left(1+0.25 \beta \sigma_{1}^{-2} R_{j}^{2} h_{j}^{2}\right)} h_{j}^{2}
$$

and the expected correlation between progeny traits $j$ and $k$ was:

$$
r_{s\left(g_{j k}\right)}=\frac{\left(r_{g_{j k}} \sigma_{I}^{2}+\beta R_{j} R_{k}\right)}{\sqrt{\left(\sigma_{I}^{2}+\beta R_{j}^{2}\right)\left(\sigma_{I}^{2}+\beta R_{k}^{2}\right)}}
$$

as

$$
\begin{aligned}
& r_{s\left(g_{j k}\right)}=\frac{\operatorname{cov}_{s}\left(g_{j}, g_{k}\right)}{\sigma_{g_{j s}} \sigma_{g_{k s}}}=\frac{\left[r_{g_{j k}}+\beta \sigma_{I}^{-2} R_{j} R_{k}\right] \sigma_{g_{j}} \sigma_{g_{k}}}{\sigma_{g_{j s}} \sigma_{g_{k s}}} \\
& =\frac{\sigma_{I}^{-2}\left(r_{g_{j k}} \sigma_{I}^{2}+\beta R_{j} R_{k}\right) \sigma_{g_{j}} \sigma_{g_{k}}}{\sqrt{\left(\sigma_{I}^{-2}\right)^{2}\left(\sigma_{g_{j}}^{2} \sigma_{g_{k}}^{2}\right)\left[\left(\sigma^{2}-I+\beta R_{j}^{2}\right)\left(\sigma_{I}^{2}+\beta R_{k}^{2}\right)\right]}}
\end{aligned}
$$

and

$$
\operatorname{cov}_{s}\left(g_{j_{p}}, g_{k_{p}}\right)=\left[r_{g_{j k}}+\beta R_{j} R_{k} \sigma_{I}^{-2}\right] \sigma_{g_{j}} \sigma_{g_{k}}
$$

and

$$
\sigma_{g_{j s}}=\sqrt{\sigma_{g_{j}}^{2}\left(1+\beta \sigma_{I}^{-2} R_{j}^{2}\right)}
$$

